\title{
Impacto do treino em habilidades de consciência fonológica na escrita de pré-escolares
}

\author{
Maria José dos Santos \\ Universidade Federal de Goiás/Regional Catalão - Catalão - GO - Brasil \\ Sylvia Domingos Barrera \\ Universidade de São Paulo - Ribeirão Preto - SP - Brasil
}

\begin{abstract}
Resumo
Pesquisas recentes demonstram que aprender a ler e escrever em uma língua alfabética exige a compreensão da relação entre fonemas e grafemas, o que requer habilidades de segmentação da fala, isto é, consciência fonológica, sendo que tais habilidades têm se mostrado altamente correlacionadas à aprendizagem da língua escrita. Nesta pesquisa tivemos como objetivo avaliar os efeitos de um programa de intervenção em consciência fonológica sobre o desempenho em tarefas de escrita em 15 pré-escolares, os quais foram submetidos a provas de consciência fonológica, conhecimento de letras e escrita de palavras antes e após a intervenção. Os resultados sugerem um efeito positivo da intervenção tanto no desenvolvimento das habilidades metafonológicas, quanto nas habilidades de escrita dos participantes. Discute-se a importância da incorporação de atividades visando ao desenvolvimento da consciência fonológica na Educação Infantil, a fim de favorecer a aprendizagem da língua escrita.
\end{abstract}

Palavras-chave: consciência fonológica; alfabetização; pré-escolares.

\section{The impact of training on phonological awareness skills in writing preschoolers}

\begin{abstract}
The recent researches shows that learning to read and write in an alphabetic language requires an understanding of the relationship between phonemes and graphemes, which requires speech segmentation skills, that is, phonological awareness, and these skills have been highly correlated with learning written language. The objective of this research was to evaluate the effects of a phonological awareness intervention program on the performance of writing tasks in 15 pre-school children, who were submitted to tests of phonological awareness, knowledge of letters and written words before and after intervention. The results suggest a positive effect of the intervention in both the development of metaphonological skills and the writing skills of participants. The importance of the use of activities aimed at the development of phonological awareness in Early Childhood Education is discussed, in order to favor the learning of written language.
\end{abstract}

Keywords: phonological awareness; literacy; Preschoolers.

\section{Impacto del entreno en habilidades de consciencia fonológica en la escritura de pre-escolares}

\begin{abstract}
Resumen
Investigaciones recientes demuestran que aprender a leer y a escribir en una lengua alfabética exige la comprensión de la relación entre fonemas y grafemas, lo que requiere habilidades de segmentación del habla, es decir, consciencia fonológica, siendo que tales habilidades se han mostrado altamente correlacionadas al aprendizaje de la lengua escrita. En esta investigación tuvimos como objetivo evaluar los efectos de un programa de intervención en consciencia fonológica sobre el desempeño en tareas de escritura en 15 pre-escolares, los cuales fueron sometidos a pruebas de consciencia fonológica, conocimiento de letras y escritura de palabras antes y tras la intervención. Los resultados sugieren un efecto positivo de la intervención tanto en el desarrollo de las habilidades meta fonológicas como en las habilidades de escritura de los participantes. Se discute la importancia de la incorporación de actividades visando al desarrollo de la consciencia fonológica en la Educación Infantil, a fin de favorecer el aprendizaje de la lengua escrita.
\end{abstract}

Palabras clave: consciencia fonológica; alfabetización; pre-escolares. 


\section{Introdução}

A capacidade de ler e escrever é fundamental para a plena participação na sociedade atual. O Brasil agrário deu espaço para um país industrializado que, cada vez mais, depende de níveis de escolaridade elevados e de qualidade. Além disso, a introdução da tecnologia na vida diária aumenta a demanda por uma população plenamente alfabetizada. Porém, muitos brasileiros não apresentam proficiência em leitura e escrita suficientes para lidar com a tecnologia presente no cotidiano. Segundo os dados da última Pnad (IBGE, 2015), o Brasil possui 8,3\% de analfabetos, ou seja, mais de 13 milhões de pessoas com 15 anos ou mais que não sabem ler nem escrever. Esse índice sobe para 17,3\% quando se consideram os "analfabetos funcionais", isto é pessoas que têm menos de quatro anos de escolaridade (IBGE, 2015).

A investigação no âmbito da leitura e das dificuldades encontradas na sua aprendizagem conduziu à identificação de competências consideradas facilitadoras da alfabetização e que, portanto, deveriam ser abordadas desde a Educação Infantil. Entre essas competências - referidas por alguns autores como competências de "letramento emergente" (Viana, Cruz, \& Cadime, 2014; Whitehurst \& Lonigan, 1998, 2003) - destacam-se: a linguagem oral (vocabulário, compreensão), os conhecimentos a respeito do material impresso, particularmente do nome e som das letras, e as habilidades de consciência fonológica, ou seja, habilidades para refletir e manipular deliberadamente os sons da língua oral. A relevância de um trabalho com essas competências na Educação Infantil justifica-se pelo seu impacto na aprendizagem da leitura e da escrita, conforme atestam sólidas evidências empíricas (Whitehurst \& Lonigan, 1998, 2003; Justice, Kaderavek, Fan, Sofka, \& Hunt, 2009, Melby-Verlag, Lyster, \& Hulme, 2012; Cruz \& cols., 2014; Viana, Cruz, \& Cadime, 2014; Reis, Proença, \& Martins, 2015).

É fato amplamente reconhecido pela literatura que as crianças tendem a se beneficiar, tanto no presente como em sua escolaridade futura, da frequência à Educação Infantil. Os estudos mostram também que os efeitos positivos da educação infantil se correlacionam com a qualidade da educação recebida e são mais significativos para as crianças de nível socioeconômico mais baixo (Campos \& cols., 2011; Melhuish, 2013). Entre os itens considerados para a avaliação da qualidade da Educação Infantil encontra-se a estruturação do currículo em geral e, de modo mais específico, as atividades pedagógicas realizadas. Nesse sentido e, de acordo com Malta-Campos (2013), pesquisas têm sugerido que abordagens curriculares centradas na criança são mais adequadas a crianças mais novas, entre três e quatro anos, sendo que um currículo mais estruturado é mais indicado para crianças a partir dos cinco anos.

Considerando o desenvolvimento da linguagem, constata-se que, ainda muito precocemente, as crianças aprendem as regras da língua oral e o fazem por meio de seu uso, não necessitando de um ensino formal. O convívio com falantes possibilita a apropriação do código linguístico e das particularidades da língua usada no meio cultural, o que permite que, ao entrarem na escola, a maioria das crianças apresente habilidades linguísticas relativamente bem desenvolvidas ao nível da articulação, vocabulário e do domínio da gramática de sua língua (Dambrowski, Martins, Theodoro, \& Gomes, 2008). Entretanto, para aprender a ler e escrever, não basta o convívio com leitores e escritores, a aprendizagem da língua escrita exige um ensino formal e sistemático, sem o qual dificilmente ocorre.

Vários são os modelos que se propõem a explicar os processos psicológicos envolvidos na aprendizagem da leitura e escrita ${ }^{1}$. Segundo o modelo de Ehri (1998, 2013), no que tange à escrita, durante o processo de sua aquisição, o aprendiz vivencia mudanças graduais na habilidade de detectar e conectar os sons percebidos na pronúncia das palavras, às unidades ortográficas adequadas. Nesse processo, é possível identificar quatro fases: pré-alfabética; parcialmente alfabética; alfabética plena e alfabética consolidada. Em cada uma delas há predominância, mas não exclusividade, de uma estratégia cognitiva.

$\mathrm{Na}$ fase de escrita pré-alfabética o aprendiz faz registros que não correspondem aos sons pronunciados nas palavras. Estudos mostram que crianças nessa fase são capazes de escrever o próprio nome e utilizam com mais frequência as letras que o compõem, embora não saibam nomeá-las, o que indica que as letras podem ser memorizadas de acordo com a frequência de exposição a seu padrão visual, antes de serem percebidas como símbolos para sons (Pollo \& cols., 2015). Aprendizagens como o nome e som das letras, bem como atenção dirigida às unidades sonoras da fala (aliterações, rimas, sílabas e fonemas) possibilitam que o aprendiz comece a compreender que as letras representam os sons das palavras, evoluindo assim em suas habilidades de escrita. Nessa segunda fase, denominada parcialmente alfabética, o aprendiz é capaz de identificar alguns sons presentes na pronúncia das palavras, geralmente sons do início e final das mesmas, e de representá-los pelas letras apropriadas. A fase alfabética plena se caracteriza pelo processamento grafofonêmico, no qual todos os sons (ou a maioria deles) identificados na pronúncia das palavras são grafados por letras foneticamente apropriadas, o que permite a escrita de palavras novas e possibilita conexões mais completas entre a ortografia e a pronúncia de palavras na memória. Na fase final, denominada alfabética consolidada, o aprendiz é capaz de fazer conexões envolvendo unidades maiores que o grafema e o fonema, sendo que os tipos predominantes de conexões retidas na memória passam a ser morfográficas (raízes, prefixos e sufixos).

Para aprender a ler e escrever em uma língua alfabética é necessário, portanto, compreender as regras do princípio alfabético de escrita, ou seja, compreender os elos entre fonemas (sons da fala) e grafemas (letras que registram os fonemas). A compreensão de tal princípio requer a habilidade de segmentar a língua falada em unidades distintas e a capacidade de perceber que tais unidades reapare-

1 Para uma revisão recente, ver Pollo, Treiman, \& Kessler, 2015. 
cem em diferentes palavras, aspectos esses relacionados à consciência fonológica.

Estudos têm sugerido também o conhecimento do nome das letras como uma condição facilitadora da aprendizagem da leitura e da escrita (Cardoso-Martins \& Batista, 2005; Ehri \& Roberts, 2006) na medida em que se constitui num aspecto fundamental para o estabelecimento das correspondências entre letras e sons que são a base para a compreensão e domínio do princípio alfabético. Reis e cols. (2015) obtiveram resultados que mostram que as crianças que revelam um maior conhecimento do nome e som das letras apresentam um nível conceitual de escrita mais elevado. Morais, Leite, e Kolisnky (2013) citam os resultados de um estudo comparativo sobre os efeitos de dois tipos de treino em consciência fonológica. No primeiro, foram treinadas apenas as habilidades de consciência fonêmica, enquanto no segundo grupo, essas habilidades foram apoiadas em atividades que envolviam as correspondências letra/som. Os resultados demonstraram que, embora ambos os tipos de treino tenham sido eficazes para o desenvolvimento das habilidades de consciência fonêmica, e mesmo para as habilidades de leitura no que se refere às crianças com maior conhecimento das letras, apenas o segundo tipo de treino foi eficaz para promover a leitura nas crianças que iniciaram o estudo com baixo conhecimento do nome das letras, sugerindo que o conhecimento das letras pode potencializar os efeitos do treino em consciência fonológica sobre a leitura.

Em 2008 foi publicado pelo National Institute for Literacy um documento intitulado Developing Early Literacy: Report of the National Early Literacy Panel (NELP, 2008) que sumariza as evidências científicas sobre a aprendizagem inicial da leitura e da escrita (early literacy). A partir da análise dos resultados de 500 pesquisas correlacionais e experimentais, foram identificadas seis habilidade que apresentam correlações preditivas de moderadas a fortes com posteriores medidas de alfabetização: conhecimento do alfabeto; consciência fonológica; nomeação rápida de letras/ dígitos; nomeação rápida de objetos/cores; escrita do nome e memória fonológica.

A consciência fonológica, ou seja, "a habilidade para detectar, manipular e analisar aspectos sonoros da linguagem falada, incluindo a habilidade para distinguir e segmentar palavras, sílabas e fonemas, independentemente de seu significado" (NELP, 2008, p. 7, tradução nossa) foi apontada pelo relatório como sendo fortemente relacionada com a aprendizagem da leitura e escrita. O relatório também indica benefícios de intervenções destinadas a promover habilidades de linguagem receptiva e expressiva e de consciência fonêmica.

Melby-Lervag e cols. (2012) relatam resultados de uma meta-análise de estudos abordando as relações entre habilidades fonológicas (consciência fonêmica, rima e memória verbal de curto prazo) e habilidades de leitura e apontam a consciência fonêmica, isto é, a habilidade de identificar e manipular fonemas, como um dos melhores preditores das diferenças individuais no desenvolvimento da leitura. Tais estudos colocam em evidência o fato de que a consciência fonológica não é uma habilidade única, mas é considerada uma habilidade cognitiva geral, composta por diferentes habilidades com níveis distintos de complexidade (Barrera \& Maluf, 2003).

Vários autores têm defendido a ideia de que os componentes da consciência fonológica (aqui identificados por habilidades metafonológicas) seguem um padrão desenvolvimental, de modo que as habilidades para analisar as unidades maiores da fala (como palavras e sílabas) seriam precursoras de habilidades de análise de unidades intrassilábicas (onset e rime) e essas, anteriores a análise e manipulação das menores unidades sonoras da fala, os fonemas (Melby-Lervag \& cols., 2012).

No Brasil, pesquisando falantes do português brasileiro, há um conjunto de estudos que apresentam evidências bem estabelecidas de que habilidades de consciência fonológica favorecem e facilitam a aprendizagem da leitura e escrita e que essas habilidades podem ser desenvolvidas por meio de programas de intervenção, conforme atesta a revisão de literatura recentemente elaborada por Barrera e Santos (2014). Essas autoras realizaram um estudo em que analisam o delineamento metodológico e os resultados de pesquisas nacionais que investigaram efeitos de programas de intervenção em consciência fonológica. Nesse estudo foram recuperados 22 artigos publicados no Brasil entre 2000 e 2012, nos quais foram analisados, entre outros aspectos, população-alvo, características do delineamento, estrutura do programa de intervenção e resultados obtidos. Dos estudos analisados, apenas quatro foram realizados com crianças da Educação Infantil, predominando as intervenções com alunos das séries iniciais do Ensino Fundamental. $\mathrm{O}$ delineamento metodológico utilizado em $95 \%$ das pesquisas foi constituído de pré-teste, intervenção e pós-teste. Em mais da metade das pesquisas analisadas, o programa foi aplicado a pequenos grupos e, na maioria das pesquisas, a aplicação foi feita pelo próprio pesquisador. Em relação à natureza das atividades metafonológicas propostas, todos os programas utilizaram atividades para desenvolver habilidades de rima e aliteração, manipulação silábica e fonêmica. As autoras apontam que $91 \%$ dos trabalhos examinados demonstraram a importância da consciência fonológica como elemento facilitador do processo de aprendizagem da leitura e escrita.

Uma das limitações percebidas nos estudos de intervenção que apontam benefícios do desenvolvimento da consciência fonológica sobre as habilidades de leitura e escrita diz respeito a certa artificialidade na implementação dos programas, os quais geralmente são aplicados em pequenos grupos e por pesquisadores. Além disso, outra lacuna observada na literatura refere-se ao fato de haver poucos estudos brasileiros com crianças da Educação Infantil. Levando em conta esses aspectos, nessa pesquisa tivemos por objetivo geral investigar os efeitos de um programa de intervenção em consciência fonológica aplicado pela professora regente de uma classe de crianças em período de pré-alfabetização. Nossos objetivos específicos foram: (1) analisar os efeitos da intervenção sobre as habilidades metafonológicas e de 
escrita dos participantes; (2) analisar a influência do conhecimento de letras como habilidade precursora do desempenho em escrita.

\section{Método}

O estudo foi realizado a partir de um delineamento quase-experimental, envolvendo as etapas de pré-teste, intervenção e pós-teste. No pré-teste foram aplicadas aos participantes tarefas de conhecimento do nome das letras, de escrita de palavras sob ditado e de avaliação das habilidades metafonológicas As mesmas tarefas foram aplicadas no pós-teste, com exceção da tarefa de conhecimento do nome das letras.

\section{Participantes}

Participaram da pesquisa 15 crianças (5 meninas e 10 meninos) matriculadas em uma Escola Municipal de Educação Infantil de Goiás, com idades entre 4 anos e 9 meses e 5 anos e 2 meses (idade média de 5 anos). A classe era composta por 20 crianças, sendo que ignoramos os dados de cinco delas: uma por apresentar problemas de linguagem expressiva, uma por ter acompanhamento na APAE e três crianças não participaram de pelo menos $70 \%$ das sessões de intervenção. Vale ressaltar que nenhuma das 20 crianças foi excluída das atividades de pesquisa.

\section{Instrumentos}

A seguir são descritas as provas utilizadas na coleta de dados, as quais constituem tarefas cujas propriedades psicométricas (validade, fidedignidade e normatização) ainda não foram estabelecidas.

Tarefa de Conhecimento do Nome das Letras (TCNL): de aplicação individual, consistiu na apresentação aleatória de todas as letras do alfabeto e solicitação de nomeação pelas crianças.

Procedimento de correção: foi atribuído 1 (um) ponto para cada acerto. Máximo de 26 pontos.

Tarefa de Escrita sob ditado (TE): de aplicação coletiva, consistiu de 22 palavras (Cardoso-Martins \& Batista, 2005). Metade das palavras foi ditada em um dia e a outra metade, no dia seguinte a fim de evitar a fadiga. Foi solicitado que as crianças escrevessem as palavras da melhor maneira que pudessem. As palavras ditadas no primeiro dia foram: beijo; dedo; queijo; veia; telefone; geladeira; zebra; bicicleta; dado; quiabo e vacina. No segundo dia foram ditadas as palavras: tartaruga; girassol; zorro; miolo; figo; limão; riacho; mandioca; faca; laranja e rapadura.

Procedimento de correção: foram utilizados os seguintes critérios: Zero: recusa-se a escrever ou não desenha letras; 1 ponto: desenha letras sem relação sonora com a palavra. Ex: Kimeiumasuj - para beijo; 2 pontos: uso de alguma letra com sonoridade pertinente à palavra, porém com omissão de letras. Ex: alo para galo; 3 pontos: escrita de palavras com erros ortográficos. Ex: mocito, moquito, musquito; 4 pontos: palavra escrita ortograficamente correta. Ex: galo, mosquito.

Tarefa de Consciência Fonológica (TCF): elaborada por Santos (2004), compõe-se de 14 tarefas. A aplicação foi individual e destinado um dia exclusivamente para essa tarefa. As Tarefas 1 e 2 avaliavam habilidades de julgamento da extensão fonológica; as Tarefas 3 e 4 consideravam habilidades de identificação e produção de rima; as Tarefas 5 e 6 avaliavam habilidades de identificação e produção de aliteração; a Tarefa 7 considerava habilidades de segmentação de frases em palavras; a Tarefa 8 avaliava habilidades de segmentação de palavras em sílabas; as Tarefas 9, 10, 11 e 12 avaliavam habilidades de manipulação silábica: omissão e acréscimo de sílabas iniciais e finais; as Tarefas 13 e 14 avaliavam habilidades de manipulação fonêmica: omissão e acréscimo de fonemas iniciais e finais.

Procedimento de correção: foi atribuído 1 (um) ponto cada item acertado. Máximo de 56 pontos.

\section{Procedimentos Éticos:}

A pesquisa foi submetida ao Comitê de Ética (Protocolo 133/2009 - CEP/UFG) e os responsáveis pelas crianças foram devidamente informados sobre os procedimentos da pesquisa e autorizaram suas participações assinando o Termo de Consentimento Livre e Esclarecido.

\section{Intervenção}

Foi aplicado um programa de intervenção em habilidades de consciência fonológica (Santos, 2008) composto por 42 atividades, distribuídas em seis unidades, durante os meses de agosto a outubro de 2009. O programa foi aplicado pela professora da turma, sob a orientação e supervisão de uma das pesquisadoras. As sessões foram diárias, com duração de aproximadamente 30 minutos. Algumas atividades foram aplicadas duas ou mais vezes, nas ocasiões em que a professora avaliou não ter ocorrido uma boa compreensão e rendimento por parte das crianças.

No início de cada sessão a professora informava às crianças os objetivos da atividade e explicava o procedimento da brincadeira. Após a realização da atividade, a professora conversava com as crianças sobre o que haviam aprendido, ressaltando a importância desse conhecimento para a aprendizagem da escrita. Ao final da aula, relatava em seu diário de campo a participação das crianças, interesses e dificuldades para então replanejar as próximas atividades.

Após as sessões de intervenção, quando a professora realizava as atividades pedagógicas constantes de seu plano de aula, sempre que possível, relacionava-as com as atividades desenvolvidas na intervenção. Em muitas ocasiões as próprias crianças faziam essa relação de maneira espontânea. 
A primeira unidade, composta por oito atividades, visava desenvolver habilidades de discriminação auditiva de forma ativa, atenta e analítica. Embora as crianças naturalmente desenvolvam essa capacidade, atividades específicas de discriminação auditiva impõem a elas o desafio de ouvir com atenção, identificando e organizando sequências sonoras. As atividades foram apresentadas numa ordem de complexidade crescente de discriminação dos sons do ambiente; relação entre sons onomatopeicos e sons da fala e identificação de semelhanças e diferenças entre sons. Exemplos de atividades: de olhos fechados as crianças nomeiam sons produzidos por objetos (chocalho, apito etc.) que estão dentro de uma caixa; de olhos fechados as crianças devem identificar e nomear sequências sonoras (por exemplo: palmas, chocalho e apito) na ordem apresentada.

A segunda unidade, com quatro atividades, visava desenvolver a consciência articulatória da fala. Segundo Santos (2008) há evidências de que a articulação consciente das palavras favorece a sensibilidade para as suas unidades fonológicas. Sendo assim, é importante que a criança articule bem as palavras e tenha consciência da articulação realizada. Exemplos de atividades: a professora apresenta caixa com objetos variados e as crianças devem nomeá-los, articulando forçadamente cada sílaba; a professora diz uma palavra no ouvido da criança e esta deverá repeti-la, articulando forçadamente a palavra ouvida. Esta criança inventa outra palavra e fala no ouvido de outra criança que deve repeti-la, articulando cada sílaba. A brincadeira segue até que todas as crianças tenham ouvido e repetido pelo menos uma palavra;

A terceira unidade, com 10 atividades, teve como objetivo desenvolver habilidades de identificação e produção de rimas. Essas habilidades são pouco exigentes cognitivamente e requerem apenas uma sensibilidade para a estrutura sonora da palavra. Exemplos de atividades: a professora lê uma história com rimas, mostrando às crianças que algumas palavras terminam com o mesmo som, incentivando-as a descobrirem outras palavras que terminam com sons semelhantes; a professora canta uma música com rimas (por exemplo: o sapo não lava o pé) no seu ritmo tradicional para garantir que todas as crianças saibam cantá-la. Em seguida canta em ritmo lento enfatizando as palavras que rimam para que as crianças identifiquem as rimas. Poderá fazer algumas variações, aumentando ou diminuindo o tom de voz nas palavras que rimam, articulando forçadamente as sílabas, batendo palmas a cada rima etc.

A quarta unidade, com seis atividades, teve como objetivo desenvolver habilidades de identificação e produção de aliteração. Assim como a habilidade de identificar e produzir rima, essa habilidade é também pouco exigente cognitivamente requerendo apenas uma sensibilidade à fonologia das palavras. As atividades são semelhantes às anteriores, porém enfatizando as aliterações.

A quinta unidade, com cinco atividades, teve como objetivo desenvolver habilidades de segmentação da frase em palavras. A consciência de que a fala é constituída de palavras não é uma tarefa simples para a criança. $\mathrm{Na}$ expressão oral as palavras não são separadas por pausas, o que dificulta a percepção da segmentação destas em uma frase. A fim de favorecer essa habilidade, foram realizadas atividades em que as crianças deviam analisar as frases em palavras separadas e pensar na sua extensão fonológica, independente do significado que veiculavam. Exemplos de atividades: a professora canta uma música (por exemplo, Marcha Soldado) no ritmo tradicional, em seguida canta lentamente, destacando cada palavra com palmas; a professora apresenta uma figura e pede a uma criança que invente uma frase com aquela palavra. A professora escreve a frase na lousa, identificando cada palavra com giz colorido, lê a frase e conta o número de palavras. Acrescenta à frase uma palavra e mostra que a frase cresceu, contando o número de palavras. Retira as últimas palavras, lê a frase e conta novamente o número de palavras, chamando a atenção das crianças para o fato da frase ter ficado menor. Na sequência ela deveria repetir o procedimento com outras frases inventadas pelas crianças.

A sexta unidade, com nove atividades, teve por objetivo desenvolver habilidades de segmentação de palavras em sílabas. Esta habilidade, de consciência silábica, tem sido apontada como uma habilidade que traz pouca dificuldade para a sua aquisição e geralmente muitas crianças desenvolvem-na de forma espontânea (Barrera \& Maluf, 2003). Entretanto, a inclusão dessas atividades se justifica na medida em que podem acelerar a compreensão das relações entre fala e escrita, além de prevenir dificuldades fonológicas que podem ser apresentadas por algumas crianças. Por exemplo, a professora apresenta uma caixa com objetos variados, pede que uma das crianças retire um objeto e nomeie. As crianças repetem o nome lentamente, contando as sílabas. Uma criança é escolhida para colocar fichas coloridas ao lado do objeto nomeado, correspondendo ao número de sílabas. Depois de ter trabalhado a consciência silábica, a professora usa os objetos para que, a partir deles, as crianças construam frases.

\section{Análise de dados}

Os dados foram analisados quantitativamente, a partir de técnicas estatísticas descritivas e inferenciais, com o auxílio do Programa Statistical Package for Social Sciences (SPSS) versão 17.0. Em função do tamanho reduzido da amostra, optou-se pela utilização de testes estatísticos não-paramétricos nas análises inferenciais efetuadas. Para a comparação da variação do desempenho dos participantes entre o pré e o pós-teste, nas Tarefas de Escrita e Consciência Fonológica, foi utilizado o Teste de Wilcoxon. A análise da relação entre o desempenho nas provas de Conhecimento do Nome das Letras, Consciência Fonológica e Escrita foi realizada por meio do cálculo do Coeficiente de Correlação de Spearman. 


\section{Resultados}

Na Tabela 1, a seguir, são apresentados os resultados da análise estatística descritiva das provas aplicadas (valores mínimos, máximos, média e desvio-padrão obtidos pela amostra de participantes), tanto no pré-teste quanto no pós-teste.

Tabela 1. Resultados da análise descritiva dos dados em função das provas aplicadas.

\begin{tabular}{|c|c|c|c|c|c|}
\hline & $\mathrm{N}$ & Mínimo & Máximo & Média & $\mathrm{DP}$ \\
\hline TCNL $(0-26)$ & 15 & 2 & 26 & 15.2 & 8.15 \\
\hline TE Pré (0-88) & 15 & 22 & 22 & 22 & 0 \\
\hline TE Pós (0-88) & 15 & 22 & 80 & 41 & 20 \\
\hline TCF Pré (0-56) & 15 & 1 & 22 & 9.53 & 5.67 \\
\hline TCF Pós (0-56) & 15 & 10 & 45 & 26.2 & 9.37 \\
\hline
\end{tabular}

TCNL $=$ Teste de Conhecimento do Nome das Letras; TE Pré = Tarefa de Escrita - Pré-Teste;

TE Pós = Tarefa de Escrita - Pós-Teste; TCF Pré = Tarefa de Consciência Fonológica - Pré-Teste; TCF Pós = Tarefa de Consciência Fonológica - Pós-Teste.

Conforme é possível observar na Tabela 1, todas as crianças investigadas obtiveram 22 pontos na tarefa de escrita realizada no pré-teste. Isso significa que suas tentativas de escrita se reduziram ao registro aleatório de números e letras sem relação sonora com a palavra ditada. $O$ registro das crianças mostra que, embora, conheçam o desenho das letras elas não fazem uma conexão entre letra e som, ou seja, não compreenderam as regras do princípio alfabético de escrita. É possível considerar, portanto, que o grupo de participantes como um todo se encontrava na fase de escrita pré-alfabética no início da pesquisa.

Também no que diz respeito às habilidades de consciência fonológica, o baixo resultado médio obtido pelos participantes - cerca de 9 pontos em 56 possíveis - indica que os mesmos apresentavam, no pré-teste, habilidades de reflexão e manipulação da língua pouco desenvolvidas.

Os resultados obtidos por meio do Teste de Wilcoxon, na comparação entre pré e pós-teste para as habilidades de consciência fonológica ( $Z=-3.061 ; p=0.002)$ e Escrita $(Z=-3.408 ; p=0.001)$, indicam uma diferença significativa entre os resultados obtidos nas duas etapas da pesquisa, apoiando assim a hipótese da efetividade da intervenção.

Uma análise mais detalhada dos dados mostrou que sete crianças ( $47 \%$ da amostra) obtiveram ganhos expressivos na tarefa de escrita após a intervenção, sendo que outros três participantes (20\%) também progrediram, porém de forma menos expressiva, enquanto as demais cinco crianças $(33 \%)$ demonstraram não ter obtido ganhos, ou seus ganhos foram muito pequenos. É interessante notar que a maior parte dessas últimas são também aquelas que apresentavam, no pré-teste, menor conhecimento das letras.

Analisando agora de forma mais detalhada a tarefa de habilidades de Consciência Fonológica, foi possível observar que 11 das 15 crianças investigadas (73\%) apresentaram um desempenho muito superior no pós-teste, indicando que eram capazes de fazer uma reflexão mais elaborada sobre a fala após terem passado pela intervenção.

Foi observado também que quatro crianças (26\%) apresentaram ganhos modestos em habilidades de Consciência Fonológica no pós-teste e não obtiveram ganhos na tarefa de Escrita. Nota-se que duas delas apresentaram níveis bastante baixos de conhecimento do nome das letras no pré-teste e as outras duas, níveis moderados.

Os resultados das análises de correlação entre as variáveis estudadas encontram-se na Tabela 2.

Tabela 2. Resultados das análises de correlação (Spearman) entre as variáveis estudadas.

\begin{tabular}{|c|c|c|c|}
\hline & TCF Pré & TCF Pós & TE Pós \\
\hline \multirow{2}{*}{$\begin{array}{l}\text { TCNL } \\
p=0,019\end{array}$} & $r_{h o}=0,60^{*}$ & $r_{h o}=0,62^{*}$ & $r_{h o}=0,75^{\star *}$ \\
\hline & $p=0,014$ & $p=0,001$ & \\
\hline \multirow[t]{2}{*}{ TCF Pré } & & $r_{h o}=0,36$ & $r_{\text {ho }}=0,44$ \\
\hline & $p=0,186$ & $p=0,105$ & \\
\hline \multirow{2}{*}{ TCF Pós } & & & $r_{h o}=0,70^{* *}$ \\
\hline & - & $p=0,004$ & \\
\hline
\end{tabular}

TCNL = Teste de Conhecimento do Nome das Letras; TE Pré = Tarefa de Escrita - Pré-Teste;

TE Pós = Tarefa de Escrita - Pós-Teste; TCF Pré = Tarefa de Consciência Fonológica - Pré-Teste; TCF Pós = Tarefa de Consciência Fonológica - Pós-Teste. 
Analisando-se a magnitude das correlações (Cozby, 2003) apresentadas na Tabela 2 , é possível concluir que o conhecimento do nome das letras apresentou fortes correlações significativas positivas com as habilidades de consciência fonológica, tanto no pré-teste $\left(r_{h o}=0,60\right)$, quanto no pós-teste $\left(r_{h o}=0,62\right)$, além de ter se correlacionado mais fortemente ainda com o desempenho em escrita no pós-teste $\left(r_{\text {ho }}=0,75\right)$. Além disso, as habilidades de consciência fonológica e o desempenho em escrita também se correlacionaram fortemente após a intervenção ( $r_{h o}=0,7$ no pós-teste).

Como as três variáveis (conhecimento de letras, consciência fonológica e escrita) se mostraram positivamente correlacionadas entre si, julgou-se necessário realizar também o cálculo da correlação parcial entre as habilidades de consciência fonológica e de escrita no pós-teste, controlando-se o efeito do conhecimento do nome das letras, tendo sido obtido um coeficiente de correlação parcial de 0,53 ( $p=$ 0,049). Calculando-se agora o Coeficiente de Explicação $\left(R^{2}\right)$ dessa correlação, podemos concluir que as habilidades de consciência fonológica conseguem explicar cerca de $28 \%$ da variabilidade do desempenho em escrita, mesmo quando se controla o efeito do conhecimento inicial do nome das letras.

Já a correlação parcial entre o conhecimento inicial do nome das letras e o desempenho final em escrita, controlando-se o efeito das habilidades de consciência fonológica é da ordem de 0,51 ( $p=0,065$ ), o que significa que esse conhecimento consegue explicar cerca de $26 \%$ da variabilidade do desempenho final em escrita dos participantes.

Realizamos ainda uma última análise, buscando identificar os efeitos da intervenção em cada uma das habilidades metafonológicas avaliadas. Para tanto, foi utilizado o Teste não paramétrico de Wilcoxon. Os resultados encontram-se na Tabela 3.

Observa-se, portanto, que, com exceção das habilidades de Rima e de Segmentação de sentenças, as quais não apresentaram mudanças significativas, todas as demais tiveram um aumento significativo após a intervenção. Entretanto, excluindo-se da análise das tarefas de rima os resultados de uma criança, cujo desempenho foi muito inconsistente (com pontuações largamente superiores no pré-teste), a comparação entre os resultados do pré e pós-teste para os outros 14 participantes resulta num valor de $Z=-1,913$ com $p=0.056$, valor esse bastante próximo da significância estatística, o que sugere que a intervenção também foi eficaz para o grupo no caso dessa habilidade metafonológica.

\section{Discussão}

A pesquisa teve por objetivo avaliar os efeitos de um conjunto de atividades voltadas para o desenvolvimento da consciência fonológica, aplicado a pré-escolares. Os resultados do estudo vão ao encontro daqueles obtidos por Santos e Maluf (2004) e Dambrowski e cols. (2008), os quais sugerem o efeito positivo do treino em habilidades metafonológicas tanto no desenvolvimento destas, quanto nas habilidades de escrita de pré-escolares. Tais resultados oferecem suporte à hipótese de que habilidades de consciência fonológica são precursoras importantes da alfabetização, conforme sustenta a abordagem do letramento emergente (Cruz \& cols., 2014; Viana, Cruz, \& Cadime, 2014; Whitehurst \& Lonigan, 1998, 2003).

Além dos progressos significativos obtidos pelo grupo de participantes nas tarefas de escrita e de consciência fonológica após a intervenção, foi possível observar também que, dentre as crianças estudadas, aquelas que apresentaram um bom desempenho em tarefas de escrita também apresentaram desempenho superior em tarefas de habilidades metafonológicas. De fato, a correlação significativa entre essas habilidades permanece, mesmo quando foi controlada a influência do conhecimento do nome das letras, fator esse que parece potencializar o efeito da intervenção metafonológica sobre as habilidades de escrita, conforme sugerido por Morais e cols. (2013). Com efeito, o conhecimento inicial dos participantes a respeito do nome das letras mostrou forte correlação significativa com as habilidades finais de escrita, o que vem corroborar os resultados de outros estudos como os de Cardoso-Martins e Batista (2005) e de Reis e cols. (2015),

Tabela 3. Resultados do Teste de Wilcoxon, comparando a diferença observada nas diversas habilidades metafonológicas, entre o pré-teste e o pós-teste.

\begin{tabular}{lcccc}
\hline Habilidades Metafonológicas & $\begin{array}{c}\text { Pré-Teste } \\
\text { (Media) }\end{array}$ & $\begin{array}{c}\text { Pós-Teste } \\
\text { (Média) }\end{array}$ & Z & $p$ \\
\hline Extensão Fonológica & 3,4 & 5,4 & $-1,998$ & $0,046^{*}$ \\
Rima & 2,27 & 2,87 & $-1,214$ & 0,225 \\
\cline { 2 - 4 } $\begin{array}{l}\text { Aliteração } \\
\text { Segmentação de Sentenças }\end{array}$ & 2,07 & 3,13 & $-1,972$ & $0,049^{*}$ \\
Segmentação de Palavras & 0,33 & 0,40 & $-0,378$ & 0,705 \\
Manipulação Silábica & 1,53 & 2,93 & $-2,858$ & $0,004^{* *}$ \\
Manipulação Fonêmica & 0,73 & 9,60 & $-3,356$ & $0,001^{* *}$ \\
\cline { 2 - 4 } & 0 & 1,73 & $-2,953$ & $0,003^{* *}$ \\
\hline
\end{tabular}


sobre a importância desse conhecimento como precursor da alfabetização.

No que se refere mais especificamente às diversas habilidades metafonológicas estudadas, constatou-se que, de modo geral, os participantes da pesquisa tiveram avanços significativos, no pós-teste, em todas as habilidades avaliadas, com exceção da tarefa de Segmentação de sentenças. Os progressos nas tarefas de extensão fonológica sugerem percepção da natureza arbitrária da realização fonológica da palavra, ou seja, a capacidade de distinguir a palavra de seu referente, o que parece ser uma condição necessária para que a criança tome a pauta sonora da fala como objeto de reflexão (Carraher \& Rego, 1981).

Foram observados também ganhos significativos nas habilidades de segmentação e manipulação silábica. Essas habilidades são apontadas pela literatura como aquelas em que a criança encontra mais facilidade, talvez pelo fato da sílaba constituir uma unidade fonológica natural. Há indícios de que, em línguas alfabéticas mais transparentes, como o português, a consciência silábica facilitaria a aprendizagem da escrita (Santos, 2004).

Com relação à habilidade de manipulação fonêmica, todas as crianças apresentaram ganhos expressivos. Resultados de pesquisas apontam que a capacidade para segmentar a palavra falada em seus fonemas constituintes é crucial na aprendizagem da escrita alfabética (Melby-Lervag \& cols., 2012). Considerando que a aprendizagem da escrita no sistema alfabético supõe associação entre grafemas e fonemas, é necessário identificar e isolar os fonemas para representá-los por letras (Santos, 2004). Entretanto, há consenso entre os pesquisadores de que tarefas de segmentação e manipulação fonêmica não são fáceis para a criança que inicia o processo de aprendizagem da linguagem escrita (Santos \& Maluf, 2004). De acordo com Morais e cols. (2013), a tomada de consciência dos fonemas, condição necessária para a compreensão do princípio alfabético, não é espontânea, mas pode ser facilitada por meio da análise e comparação de sílabas faladas e escritas, o que explicaria a importância da consciência silábica para a aprendizagem da escrita, ao menos em línguas de estrutura silábica mais saliente, como o português

Apenas uma habilidade metafonológica - segmentação das sentenças - não mostrou aumento estatisticamente significativo com a intervenção. Com efeito, a literatura tem apontado que o conceito de palavras é de difícil compreensão para as crianças em processo de alfabetização (Barrera \& Maluf, 2003; Ferreiro \& Pontecorvo, 1996), o que faz com que, mesmo após terem compreendido e dominado as regras básicas de correspondência entre grafemas e fonemas, seja relativamente frequente a observação de erros de segmentação lexical na escrita (Correa, Dockrell, \& Zyngier, 2014).

Embora os resultados de pesquisas sugiram que as habilidades de segmentação e manipulação fonêmica sejam altamente dependentes de instrução formal (Morais, 1996), há que se ressaltar que no programa aplicado a essas crianças, não havia atividades específicas para o desenvolvi- mento dessas habilidades. Diante do resultado apresentado pelas crianças, temos duas hipóteses: as crianças generalizaram o conhecimento em segmentação silábica para a segmentação fonêmica ou a prática pedagógica cotidiana da professora possibilitou o desenvolvimento dessa habilidade.

Os resultados obtidos corroboram a hipótese de que as habilidades de manipulação silábica são anteriores às habilidades de manipulação fonêmica (Barrera \& Maluf, 2003; Morais \& cols., 2013), e que estas estão mais diretamente relacionadas à aprendizagem da escrita (Melby-Lervag \& cols., 2012). De fato, todas as crianças que apresentaram bom desempenho em tarefas de manipulação fonêmica apresentaram também bom desempenho em tarefas de manipulação silábica, embora o inverso não seja verdadeiro. Além disso, das oito crianças que demonstraram bom desempenho em tarefas de escrita, sete demonstram alguma habilidade em manipulação fonêmica.

\section{Considerações Finais}

Acredita-se que o estudo trouxe importante contribuição para a elaboração de práticas pedagógicas que possam favorecer a aprendizagem da linguagem escrita, tornando o processo mais agradável, prazeroso e significativo para as crianças, uma vez que, de modo geral, observou-se grande interesse das mesmas pelas atividades propostas. Assim, a inclusão de atividades metafonológicas desde os últimos anos da Educação Infantil poderá aumentar as chances de sucesso das crianças diante do desafio da aprendizagem da escrita, diminuindo as possibilidades de fracasso na alfabetização.

Conforme demonstrado nesta e em outras pesquisas (Barrera \& Santos, 2014; Dambrowski \& cols., 2008; Morais \& cols., 2013; Santos \& Maluf, 2004), a consciência fonológica facilita a compreensão do princípio alfabético, favorecendo a aprendizagem da correspondência entre letras e sons. Além disso, a consciência da estrutura sonora da fala pode ser estimulada por meio de atividades específicas, através de práticas pedagógicas lúdicas que incorporam jogos de linguagem destinados a favorecer o desenvolvimento da consciência fonológica, desde o período pré-escolar. Sugere-se, portanto, que atividades voltadas para o desenvolvimento da consciência fonológica façam parte, sistematicamente, dos conteúdos de possíveis programas destinados aos últimos anos da Educação Infantil, cuja melhor estruturação pode contribuir para impactar positivamente toda a trajetória escolar dos alunos (Campos \& cols., 2011; Melhuish, 2013).

O estudo apresentado mostra-se relevante na medida em que foi realizado em condições naturais de situação escolar e com uma amostra representativa do número de crianças que costumam ser atendidas em classes de Educação Infantil, aproximando, assim, a situação da pesquisa do ambiente real da sala de aula, aumentando, portanto, sua validade externa. Porém, o fato de o estudo não utilizar grupo controle para isolar os efeitos da intervenção de outras possíveis variáveis concorrentes, constitui uma limitação da 
pesquisa. Outra limitação diz respeito às provas utilizadas na coleta de dados não possuírem parâmetros psicométricos estabelecidos, sobretudo no caso da prova de escrita, que apresentou problemas para discriminar de forma mais precisa os conhecimentos iniciais da amostra estudada. Sugere-se, portanto, a necessidade de novos estudos que possam contemplar as limitações apontadas. Seria importante também avançar no sentido da realização de estudos de intervenção com pré-escolares que visem também ao desenvolvimento da consciência fonêmica e ao conhecimento do alfabeto, uma vez que essas habilidades têm sido apontadas pela literatura como as principais precursoras da aprendizagem da leitura e da escrita.

\section{Referências}

Barrera, S. D. \& Santos, M. J. (2014). Influência da consciência fonológica na aprendizagem da leitura e escrita: o que dizem as pesquisas brasileiras. Em J. P. Oliveira, T. M. S. Braga, F. L. P. Viana \& A. S. Santos (Orgs), Alfabetização em países de língua portuguesa (pp. 27-41). Curitiba: CRV.

Barrera, S. D. \& Maluf, M. R. (2003). Consciência metalinguística e alfabetização: um estudo com crianças da primeira série do ensino fundamental. Psicologia: Reflexão e Crítica, 16(3), 491-502.

Campos, M. M., Esposito, Y. L., Bhering, E., Gimenes, N., \& Abuchaim, B. (2011). Qualidade da educação infantil: um estudo em seis capitais brasileiras. Cadernos de Pesquisa, 41(142), 20-54.

Cardoso-Martins, C. \& Batista A. C. E. (2005) O conhecimento do nome de letras e o desenvolvimento da escrita: evidência de crianças falantes do Português. Psicologia: Reflexão e Crítica, 18(3), 330-336.

Carraher, T. N. \& Rego, L. L. B. O. (1981). Realismo nominal como obstáculo na aprendizagem da leitura. Cadernos de Pesquisa, 39, 3-10. Recuperado: 10 mai. 2015. Disponível: http://educa.fcc.org. br/scielo.php?pid=S0100-5741981000400001\&script=sciarttext

Correa, J., Dockrell, J., \& Zyngier, S. (2014). A ocorrência de hipersegmentação na escrita e o desenvolvimento do conceito de palavra morfológica. Em A. Roazzi, F. V. Paula, \& M. J. Santos (Orgs.), Leitura e escrita: a sua aprendizagem na teoria e na prática (pp. 41-54). Curitiba: Juruá.

Cozby, P. (2003). Métodos de pesquisa em ciências do comportamento. São Paulo: Atlas.

Cruz, S. J., Almeida, M., Pinto, P., Constante, P., Macedo, A., Amaral, J., Monteiro, L., Lopes, E., \& Ferreira, C. (2014). Contribuições da literacia emergente para o desempenho em leitura no final do $1^{\circ}$ CEB. Análise Psicológica, 32(3), 245-257

Dambrowski, A. B., Martins, C. L., Theodoro, J. L., \& Gomes, E. (2008). Influência da consciência fonológica na escrita de pré- escolares. Revista Cefac, 10(2), 175-181.

Ehri, L. (1998).Learning to read and learning to spell are one and the same, almost. Em C. Perfetti, L. Rieben, \& M. Fayol, (Orgs.), Learning to spell: research, theory and practice across languages (pp. 237-269). Mahwah: Erlbaun.

Ehri, L. (2013). O desenvolvimento da leitura imediata de palavras: fases e estudos. Em M. Snowling e C. Hulme (Orgs), A ciência da leitura (pp.153-172). Porto Alegre: Penso.

Ehri, L. \& Roberts, T. (2006). The roots of learning to read and write: acquisition of letters and phonemic awareness. Em R. Dickinson e S. Neuman (Orgs.), Handbook of early literacy (pp. 113-131, vol. 2). New York: Gulford Press.

Ferreiro, E. \& Teberosky, A. (1985). Psicogênese da língua escrita. Porto Alegre: Artes Médicas

Ferreiro, E. \& Pontecorvo, C. (1996). Os limites entre as palavras: a segmentação em palavras gráficas. Em E. Ferreiro, C. Pontecorvo, N. R. Moreira, \& I. G. Hidalgo (Orgs.), Chapeuzinho Vermelho aprende a escrever: estudos psicolinguísticos comparativos em três línguas (pp. 38-66). São Paulo: Ática.

IBGE (2015). PNAD - Pesquisa Nacional por Amostra de Domicílios. Síntese de Indicadores 2014. Recuperado: 15 set. 2015. Disponível: http://www.ibge.gov.br/home/presidencia/noticias/ imprensa/ppts/00000024052411102015241013178959.pdf

Justice, L., Kaderavek, J., Fan, X., Sofka, A., \& Hunt, A. (2009). Accelerating preschoolers' early literacy development through classroom-based teacher-child storybook reading and explicit print referencing. Language, Speech, and Hearing Services in Schools, 40, 67-85.

Malta-Campos, M. (2013). Entre as políticas de qualidade e a qualidade das práticas. Cadernos de Pesquisa, 43(148), 22-43.

Melby-Lervag, M.; Lyster, S. A., \& Hulme, C. (2012). Phonological skills and their role in learning to read: a meta-analytic review. Psychological Bulletin, 138(2), 322-352.

Melhuish, E. (2013). Efeitos de longo prazo da Educação Infantil: evidências e política. Cadernos de Pesquisa, 43(148), 124-149.

Morais, J. (1996). A arte de Ler. São Paulo: Editora UNESP.

Morais, J., Leite, I. \& Kolinsky, R. (2013). Entre a pré-leitura e a leitura hábil: condições e patamares da aprendizagem. Em M. R. Maluf. \& C. Cardoso-Martins (Orgs.), Alfabetização no século XXI: como se aprende a ler e escrever (pp. 17-48). Porto Alegre: Penso.

National Early Literacy Panel. [NELP] (2008). Developing early literacy: Report of the National Early Literacy Panel. Washington, DC: National Institute for Literacy. Recuperado: 16 ago. 2015. Disponível: http://www.nifl.gov/earlychildhood/NELP/NELPreport. 
html

Pollo T. C., Treiman, R., \& Kessler, B. (2015). Uma revisão crítica de três perspectivas sobre o desenvolvimento da escrita. Estudos de Psicologia, 32(3), 449-459.

Reis, A., Proença, M., \& Alves-Martins, M. (2015). Relação entre o nível conceptual de escrita, o conhecimento do nome das letras e a consciência silábica e fonêmica em crianças de idade pré-escolar. Em L. Mata, M. Alves Martins, V. Monteiro, J. Morgado, F. Peixoto, A.C. Silva, \& J. Silva (Orgs.), Atas XIII Colóquio Internacional de Psicologia e Educação (pp. 284-298). Lisboa: ISPA.

Santos, M. J. (2004). Consciência Fonológica e Educação Infantil: aplicação de um programa de intervenção e seus efeitos na aquisição da escrita. Tese de Doutorado. Pontifica Universidade Católica de São Paulo, São Paulo.
Santos, M. J. (2008). Programa de Intervenção em Consciência Fonológica.

Manuscrito. Programa elaborado em Estágio de Pós-Doutorado na Pontifícia Universidade Católica de São Paulo/SP.

Santos, M. J. \& Maluf, M. R. (2004). Consciência Fonológica e linguagem escrita: efeitos de um programa de intervenção. Em M. R. Maluf(Org), Psicologia Educacional: questões contemporâneas. (pp. 91-103). São Paulo: Casa do Psicólogo.

Viana, F. L., Cruz, J., \& Cadime, I. (2014). "Ler" antes de ler. Como facilitar a aprendizagem da leitura e da escrita? Em F. L. Viana \& I. Ribeiro (Orgs), Falar, Ler e Escrever: propostas integradoras para o Jardim da Infância (pp. 06-23). Lisboa: Santillana.

Whitehurst, G. J. \& Lonigan, C. J. (1998). Child development and emergent literacy. Child Development, 69 (3), 848-872.

\section{Sobre as autoras}

Maria José dos Santos (majossantos@gmail.com)

Doutora. Universidade Federal de Goiás/Regional Catalão

Sylvia domingos Barrera (sdbarrera@ffclrp.usp.br)

Doutora. Universidade de São Paulo / Faculdade de Filosofia, Ciências e Letras de Ribeirão Preto - USP. 